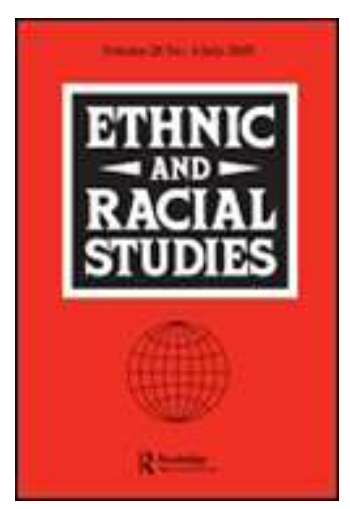

\title{
Measuring ethnicity: challenges and opportunities for
} survey research

\begin{tabular}{|r|l|}
\hline Journal: & Ethnic and Racial Studies \\
\hline Manuscript ID: & RERS-2009-0224.R2 \\
\hline Manuscript Type: & Original Manuscript \\
\hline Keywords: & $\begin{array}{l}\text { Ethnic Identity, Ethnicity, Ethnic Groups, survey data, Census, } \\
\text { Categories }\end{array}$ \\
\hline \multicolumn{2}{|c}{} \\
\hline
\end{tabular}

\section{ScholarONE \\ Manuscript Central}




\title{
Measuring ethnicity: challenges and opportunities for survey research
} Jonathan Burton, Alita Nandi and Lucinda Platt

\begin{abstract}
Measuring ethnic identity in social surveys has traditionally been problematic, often using a single question and allowing the respondent to choose one category from a pre-defined list. In this paper we discuss the rationale for and limitations of measuring a complex and multi-dimensional concept with a simple, unidimensional question. We propose that operationalising ethnicity as multidimensional requires multiple questions to capture the complexity of the concept. Giving researchers a number of different measures enables them to focus on the dimensions of interest to them, and has the potential to open up the rich resources of theoretically-robust survey research to researchers from a range of disciplines concerned with questions of ethnic identification.
\end{abstract}

Keywords: ethnic identity; ethnicity; ethnic groups, survey data; census; categories

\section{Introduction}

At least since Weber, extensive analytic and conceptual effort has been dedicated to defining ethnicity and its relationship to other components of identity, behaviour and expression. Much discussion highlights its fluid and contingent nature, the ways in which ethnic boundaries are formed or the conditions under which they come into being, and the situational nature of ethnicity (Wimmer, 2008, Helbling, 2009, Hitlin et al., 2006, Brown et al., 2006). 
By contrast, standard measures in surveys and censuses aim for stability and present the respondent with relatively crude fixed categories. Some analysts, working with qualitative insights into the complexity, temporal and geographical specificity and multiplicity of ethnic identifications, and frustrated by the lack of conceptual coherence in standard measures, have rejected census and survey measures as being inadequate to the task of informing us about ethnicity, or as used to buttress stratifying processes (Zuberi and Bonilla-Silva, 2008). Yet there remains substantial demand from research and policy perspectives for engaging with issues of ethnicity in survey research, and for carrying discrete measures that can be implemented in a survey context.

Rather than urging the separation of analysis of ethnicity from ethnic group survey measures, we suggest that there might be ways to bring them together more effectively (Nobles, 2002). By engaging both with qualitative insights into multiple affiliations and the multi-dimensionality of ethnicity and with the practical insights of survey methodology into the logic of question setting and the ways responses are shaped, we suggest that it may be possible to find a way of measuring ethnicity in surveys that avoids some of the pitfalls of current categorical questions, has greater conceptual rigour and is amenable to analysis across a wide range of disciplines and research interests.

To this end, we critically review why measuring ethnic identity has been problematic, and reflect on whether there is a way forward focusing on the UK. While the issues around ethnic group measurement have been extensively 
debated, and specialist surveys have set out to provide greater sensitivity and theoretical underpinning to the deployment of questions and the constructs measured (Modood et al., 2002), there have been few advances in how to address the measurement of ethnic identity in generalist surveys, nor the methodological issues that are necessarily implicated in such an attempt. This is the contribution of this paper. The UK is rich in such general survey data and most surveys carry some measure of ethnic group, typically the recommended census categories, which are used for a substantial amount of research. This is a reality it is important to engage with (Aspinall, 2000); but there is a need for enhancing or complementing such measures to increase the potential of quantitative ethnicity research.

We identify three main issues in current survey and census questions. First, the central issue is the problem of measuring a dynamic and multidimensional concept, ethnicity, using a single categorical question. Second, and related, is that researchers themselves bring different understandings of ethnicity and ethnic identity to their investigations and thus have different expectations of what any given measure can - or should - deliver. A researcher interested in individual acquisition of (subjective) identity will want to ask about ethnic identity in a different way to, for example, a population-level researcher looking at discrimination across 'objective' groups (those defined, for example, by first language, country of birth or migrations status) in the labour market.

The third key issue is the effectiveness of a given survey measure or set of measures. There are some practical measurement issues that need addressing if 
surveys are to improve the extent to which they meet existing and evolving research interest in ethnicity. We conclude that asking series of questions across multiple domains, rather than offering simply a single category, and paying attention to question wording and context, it may be possible to go some way towards addressing both the multi-dimensionality of ethnicity and providing flexibility in meeting the varied demands of researchers within a multi-purpose survey.

\section{The problem with categories}

Issues of identity, ethnic diversity, and differences between the UK's ethnic groups are substantial research and policy interests. The UK also offers a wealth of multi-purpose surveys that can be used to analyse the experience of different ethnic groups and to highlight inequalities between them: surveys with minority boost samples, both cross sectional and longitudinal, and repeat cross-sectional surveys that can be pooled to increase sample sizes (see: http://www.dataarchive.ac.uk/). However, in general, they use a standard question developed for and utilised in the decennial population Census to define ethnic group. While the categories in this question broadly differentiate between histories of particular post-war immigrant experiences (Coleman and Salt, 1996b, Peach, 1996), they have been subject to extensive criticism relating to both their conceptual basis and their operational use (Ballard, 1997, Ballard, 1996, Ratcliffe, 1996, Aspinall, 2001a).

Critics highlighted in particular the fact that different categories used different criteria for defining or conceptualising ethnicity, leading to conceptual 
confusion. Ballard (1997) argued that the question reinforced a racialised perception of the world that had no analytical acceptablity; and Ratcliffe was led to state that 'what is clear about the census ethnic group question is that the one thing it does not measure is ethnicity' (Ratcliffe, 1996 p.5).

\section{The multi-dimensional nature of ethnicity}

At the heart of these criticisms is the conundrum of attempting to divide the population into a set of mutually exclusive categories using a single question. That is, treating a multi-dimensional, fluid, and contextually and relationally specific concept as if it were uni-dimensional, fixed and stable (Aspinall, 2001b, Yancey et al., 1976, McDonnell and de Lourenco, 2009). Instead we need to recognise that ethnicity and ethnic group identification are contingently located in one or more characteristic or expression of shared belonging. These 'dimensions' may include 'race' (or colour or visibility); national identity (Jackson and Smith, 1999); parentage or ancestry (Berthoud, 1998); nationality; citizenship (Kymlicka, 1996, Hussain and Bagguley, 2005); religion; language (Phinney et al., 2001, Vedder and Virta, 2005), and country of birth (or being an immigrant), as well as the problematic domain of 'culture' (Geertz, 1993, Ahmad and Bradby, 2007), which we consider here as behavioural and attitudinal and discuss separately from issues of identification (Modood, 1997). The extent to which any such 'dimensions' or combinations of dimensions are relevant to the construction of and identification with any group will vary according to group, to context and over time (Nazroo and Karlsen, 2003, Modood et al., 1994, Warikoo, 2005). Researchers' and their conceptual constructions of ethnicity also differ in ways that imply particular demands on measures. 
Finding a simple way of meaningfully summarising ethnic group therefore invites problems as there are no 'essential' components and there is no continuous concept of single groups. It is virtually impossible to create single, mutually exclusive categories for ethnicity measures which are both conceptually coherent and which invite recognition and identification from respondents.

\section{Subjective identification and preconceived groups}

As Weber (1978) pointed out, what is central to the definition of ethnic groups is 'a subjective belief in their common descent', even though 'it does not matter whether or not an objective blood relationship exists' (Weber 1978: 389). Despite some debate on 'objective' measures versus self selection (Smith, 2002, Modood et al., 2002), this emphasis on self-conscious identification is widely accepted including by census bureaux and statistical offices (Martin and Gerber, 2006, Office for National Statistics, 2003), but may serve to introduce confusion where the actual object of a question has little to do with expressive identity.

For the UK's first ethnic group question in a census, in 1991, the question was framed as a measure of subjective ethnic group, and about identification. However, both commentary on the UK 1991 question and the approach used to collect the ethnic group information emphasised that what was of interest was in fact the 'non-white' population (Salt, 1996, Coleman and Salt, 1996a). Thus the logic seemed close to understandings of race questions in US questions despite the explicit rejection of the language of race in favour of a concentration of the 
language of ethnicity in the UK, and the very different solutions to the construction of ethnic group questions.

Not only governments but also many analysts are interested in stable measures which help them understand population trends and experiences across population subgroups including ethnic (or in US terms, racial) groups (Kertzer and Arel, 2002). There are important policy drivers for such stable measures, such as having sufficient information to meet the requirement to monitor policy and service delivery for different ethnic groups (Bulmer 1986). A reporting requirement is also behind the race and ethnicity questions in the US census (Anderson and Fienberg, 1999). In both countries, the construction of groups is based on politically salient categories, though of course what is politically salient is highly locally specific, and renders international consideration of groups on the basis of ostensibly self-ascribed categories essentially meaningless.

To equate such monitoring systems with individuals' identification is highly problematic (Bonnett, 2000). Official categorisations represent systems of power and authority which prejudge who are minorities or 'others' and the implicit or explicit bases on which they are to be distinguished - even if such presumptions are later contested (Howard, 2006). For example, the ways in which 'write-in' answers in the UK censuses are reallocated to the main categories on offer clearly illustrates the prioritisation of official views on where people 'fit' (Office for National Statistics, 2003). Legal and political considerations and mobilisation frame the circumstances under which categories adjust over time. The need of ethnic minority groups to be heard in a democracy 
may lead to formation of new ethnic identities or redefinition of existing ones (Urla, 1993). Certain groups may lobby for inclusion and the recognition that offers (Howard, 2006). Conversely, there may be political arguments against the introduction of new categories: the multiple response race question in the U.S. census was met with opposition from certain black interest groups who feared that this would lead to a reduction in the proportion of respondents reporting as black (Skerry, 2000, Farley, 1997), as 6.8 million people took up the opportunity to chose two or more races (LEA AND BEAN).

Even if respondents provide answers to the categories offered, they may not be providing even approximate information on their self-identification, since responses can be 'learnt', without necessarily increasing the relevance of categories to analysts (Kertzer and Arel, 2002). Martin and Gerber (2006) point out that pre-designated categories imply that these are the 'correct' categories and may constrain people to report within categories that they do not identify with. When asking an open-text unprompted ethnicity question and the existing Census ethnicity question, Pringle and Rothera (1996) found that there was an exact or near exact match in only 28 per cent of the valid responses; while Lopez (2003) showed that two-fifths of respondents would give different or additional responses if faced with a multiple response question rather than a single-response set of categories.

It is clear then that even if current census categories have a role, they cannot be expected to provide an adequate understanding of the diversity and development of subjective ethnic identities. 


\section{Improving on categories}

For some, the perceived problems of using one single-response categorical question have resulted in a rejection of survey research of ethnicity, or to its construction as malign or dangerous. See, for example, the discussions in Blum (2002), Bhavnani et al. (2005) Bonnett and Carrington (2001). Proxies for ethnic group membership based on family origins have also been subject to critiques (Smith, 2002, Cole, 2003). While we recognise the criticisms, we argue that the alternative is to focus on developing better measures.

What is important is that respondents are offered the opportunity to define themselves - and express strength of identification - in relation to those aspects that are meaningful and matter to themselves. Allowing multiple responses across differing bases of potential affiliation, has been shown to be popular with respondents and may help to achieve this. Such measures are also relatively transparent and do not imply that they are being asked to fit into a single 'box'. They also allow researchers to ascertain what it is that divides and joins 'groups' along these dimensions and facilitate the construction of conceptually coherent 'groups' for research purposes. Identifying the content of each of the dimensions (the respondent's country of birth, her religion her parents' country of birth, and so on) will not only enable an empirical understanding of groupness, based on strength of identification; also better meet the needs for 'objective' measures that are relatively stable than questions that ask for self-identification. For some analysts particular dimensions will be of interest in their own right, and to be able to focus only on those dimensions - and 
on those respondents for whom they are salient - will promote conceptual clarity and the 'fit' of measures to particular research agendas.

Such an approach would, then, allow flexibility for researchers both in their constructions of ethnicity and in the research questions they are able to address. There will, of course remain questions that are not susceptible to empirical survey analysis, and social surveys can never address the full range of questions that are of concern to ethnicity researchers. But that is not to say that they cannot do a better job and cover far more than they do currently. Increasing the flexibility of responses so that researchers can focus on the dimensions that are of interest may also serve to enable meaningful cross-national comparison, given that ethnicity is differently defined and categorised according to national context. For example, the UK and the US operate with very different conceptions of ethnicity, which, in the US, is distinguished from race. This makes harmonisation of categorical questions well-nigh impossible. The proposed approach based on collecting information about multiple general dimensions could be deployed in contexts where concepts (and language) of race and ethnicity and very different.

\section{Constraints on identification}

However, it is not simply in potentially multiple dimensions of identity and identification that ethnicity resides. Returning to the issue of subjective identification, as well as defining ethnicity by "a sense of belonging", others have defined groups in relation to how they construct difference from others and 
establish boundaries for the groups (Wimmer, 2008, Min and Kim, 2009). This is a perspective that is associated with Barth's work (Barth, 1969); but has also been stressed by the acculturation framework, which focuses on the juxtaposition of two cultures in rendering the concept of ethnic identity meaningful. Individual ethnic identification is limited by external forces that shape the options, feasibility and attractiveness of various ethnicities (Nagel, 1994, Salway, 2008, Ryan, 2007). These external factors include attitudes and responses of others (Golash-Boza and Darity, 2008), but also the use of official categories in censuses and monitoring forms themselves (Jenkins, 1994). It is therefore important that the external constraints and impulses to particular forms of identification are also captured, both through recognising - and repeating existing forms of labelling, and through attempting to measure own and other group attitudes as well. Thus questions on apparently 'innocent' dimensions of identity also need to be complemented by measures of prejudice and of ownership of ethnic identity.

\section{Lived ethnicity}

Finally, in addition to relational aspects of ethnicity, there are also behavioural aspects: how people use their time, who they associate with and so on. To assume that identification with a particular category implies particular sets or patterns of behaviour of association is potentially to overload those categories yet further. Instead, behaviour or 'involvement' could be conceived of as an additional 'dimension' that may be present in some research formulations of what an 'ethnic group' means - or may be investigated in relation to particular constructions of ethnic group (Nazroo and Karlsen, 2003, Min and Kim, 2009). 
When considering the survey measurement of ethnicity, then, it is important to consider not only multi-dimensional measures of identity and identification, but also to collect complementary information on intergroup relations and on patterns of behaviour. Phinney (1990) identifies five components of ethnicity, which are often merged or overlap in usage of the terms 'ethnicity' or 'ethnic group': ethnicity by which she means a person's heritage, parents' ethnicity, country of origin; self-identification as a member of an ethnic group; ethnic belonging, which refers to a sense of belonging to the selfidentified ethnic group/s; ethnic involvement or participation and practice of being a member of an ethnic group; and ethnic attitude, which refers to one's opinion towards one's self-identified ethnic group. Though we might dispute the precise components or the terminology, the attempt to break down ethnicity into elements which can be separately measured and which can be jointly or separately analysed appears to be a positive way forward for the operationalisation of ethnicity within social surveys (McKenzie and Crowcroft, 1996, Senior and Bhopal, 1994, Singh, 1997), even to those somewhat sceptical about the feasibility of unpacking ethnicity (McKenzie, 1998).

\section{The fluidity of ethnicity}

To capture issues of context, contingency and change, it is also important to consider the survey context, or the type of survey in which ethnic identity might most effectively be measured. Having responses from different family members, specifically parents (partners) and children and their siblings allows a detailed exploration of the how those sharing a common family background 
differ in their subjective identifications. Qualitative studies are beginning to demonstrate how within family, specifically between siblings, identification can vary; and surveys that, as many do, collect information on multiple, cohabiting family members can offer a valuable complement to such research. Longitudinal surveys can enable research into ethnic identity development and distribution of identities both over time and for different cohorts. (See Umana_Taylor et al. (2009) on the benefits of longitudinal surveys for measurement.) Much of the psychological literature on ethnic identity focuses on young people who are assumed to be at the most flexible stage of their development (Phinney, 1990, Phoenix and Tizard, 1995, Hitlin et al., 2006, Hsiao and Wittig, 2008); but it would be valuable to explore the temporal processes operating among adults, such as migration or the arrival and departure of family members, about which we know much less.

\section{Asking ethnic group questions: issues and practice}

What, then, are the practical implications in collecting measures of identification across multiple dimensions and of experience and perception across multiple domains? Many of the insights into the multidimensionality of individuals' experience and expression of ethnicity have come from qualitative research. To translate these insights into effective survey measures requires recognition of the constraints of survey questions, the need to ensure validity of responses relative to the concept being measured, as well as ensuring acceptability and maximising response. To this end we can take stock of the lessons that have been learnt in 
setting and modifying standard categorical questions and be alert to the potential pitfalls.

Moreover it is important to recognise that not even well-designed questions can facilitate research in all areas of interest to understanding ethnicity. Issues relating to personal narratives, to the role of wider family kin and to peer groups in forming personal identities, as well as the investigation of very specific groups, such as transnationally adopted children, will continue to remain best addressed by qualitative research. But even with such research, a more general understanding of identification may provide important context and starting points.

\section{Measurement issues}

We noted above that census bureaux stress the subjectivity of responses even while attempting to measure an assumed objective reality. Part of the emphasis on subjectivity is a genuine recognition of the conceptual discussions relating to ethnicity and that it is not fixed. Part is a recognition that it would be impossible to consider any other way of ascertaining people's ethnic group other than by asking them: co-operation from respondents is a prerequisite for collection and thus acceptability becomes a crucial consideration for the specification of categories (Sillitoe and White, 1992, Maylor, 2009). This raises the general point that if categories or domains used in questions do not make sense to the respondents then there will be a lot of item non-response or 'other' reporting (Bonnett and Carrington, 2001). Bates et. al. (2006) also reveal the substantial frustration that can arise when ethnic categories are felt to deny preferred 
identifications. And when interviewers themselves find questions ambiguous they try to resolve these issues differently, resulting in interviewer effects on the responses (Martin and Gerber, 2006). Questions therefore need to reflect concepts that are straightforward and meaningful to respondents, whether or not they identify with them. Dimensions such as country of birth and religious affiliation are relatively clear, others concerning main/first language, colour or nationality may require some care in matching the intended concept to the word or phrase used in a question.

Another potential source of measurement error that we discussed is 'learning' the expected response. When people 'learn' a response through exposure to the Census question (or alternatively learn to resist it), this potentially increases the stability, but not necessarily the meaningfulness of the data. The acceptability of, and even preference for, multiple response categories has been regularly demonstrated (Lopez, 2003, Callister et al., 2007); and illustrates that such questions offer a preferable means to improve reliability than through attempting to shoe-horn respondents into preconceived matches.

Learning also requires time and familiarity. So, while it may deliver the 'right' responses in some cases, it is less likely to do so for new or recent immigrants - groups potentially of great interest for governments as well as researchers. Those who have recently migrated initially retain the concept of ethnicity of their country of origin. For example, Martin and Gerber (2006) find that persons from Central and South America and the Caribbean do not think race and ethnicity are separate concepts and would like to choose the country 
they have come from as their race/ethnicity (see also Massey (1993) McDonell and de Lourenco (2009)). Over time, classification systems can shape not only responses but also self-identification (Itzigsohn et al., 2005), given the relevance of how others see you (or your perception of it) to your identity. But to allow investigation of new populations and the process of identity formation and development, it is important that measures and the categories they employ are comprehensible to new migrants as well as established populations. Avoiding questions which directly invoke concepts of race or ethnicity, which are known to vary widely across contexts is one potentially important strategy (Bhopal, 2002). Such a strategy is eased in context of multiple domains rather than mutually exclusive categories.

But achieving reliable responses and the acceptability of questions is not simply a matter of the categories asked. Positioning of questions is explicitly used to increase the numbers completing the 'right' box (Bates et al., 2006, Martin et al., 1990). In the UK 2011 census, the proposed placing of a national identity question prior to the ethnic group question is designed to allow all those who wish to assert their Britishness to have an initial opportunity to do so, with the intended result that fewer minorities will 'incorrectly' subsequently select the British sub-option of 'white' or use the write-in sections to define themselves as British. Sometimes composite categories are used for the same purpose. In the 2001 Census "Black British” and “Asian British” options were included as a way of allowing people to state their Britishness in addition to their ethnicity. This returns us to issues of acceptability and maximising response, by offering options that explicitly match on to people's preferred ways of seeing themselves. 
Without overloading respondents it is clearly important to provide sufficient domains to meet their requirements for expressing their sense of who they are. Rather than the continual increase in single categories that has categorised the UK Census questions, allowing responses over multiple shorter measures, should reduce list effects and the effort required from respondents.

There are of course other general issues of question design that we need to be aware of. Responses may differ depending on the method of the interview (face-to-face, telephone or self-completion); and mode effects may be specifically related to dimensions of ethnicity. For example, those who do not understand English are less likely to complete a mail questionnaire and are thus interviewed face to face, which affects response; but those with limited grasp of English also tend to report ethnicity differently from those who do have a strong grasp of English (Martin and Gerber, 2006). Understanding the impact of such variation may be important in designing new questions for multiple or single modes.

As well as 'recency' or 'primacy' effects - a danger with categorical ethnic group questions that may have up to seventeen categories - there may also be different responses according to whether there are other people present during the interview who could influence their responses. Studies have found differences in responses depending on the interview location such as at home vs. at school (Harris and Sims, 2002). Persons of mixed parentage may choose different ethnic group identities depending on which parent is present at the time of the interview (Martin and Gerber, 2006, Xie and Goyete, 1997, Phinney, 1992, 
Holloway et al., 2009). Others may wish to claim more than one of the offered categories and may resist being forced to choose (Aspinall, 2000) or allocate themselves arbitrarily between the options proffered. It is important both to know the context and to be able to standardise it across respondents as far as possible (for example, by giving respondents a questionnaire to complete privately), and to ensure that multiple affiliations are possible.

Nevertheless, techniques to improve the question design may not resolve consistency issues (i.e., stable responses over time) that arise because these questions are asking people to pick their ethnic identity which is inherently subjective and therefore subject to change with the context of the question and the questioning. For example, a person's choice of ethnic group label may be correlated with how she views her ethnic group vis-à-vis the mainstream dominant group (Hecht and Ribeau, 1991). Changes in identification may occur through the development of ethnic identity (along with other aspects of identity) over a person's life (Phinney and Alipuria, 1990).

If ethnic groups are considered as composites of characteristics and affiliations, it may be possible to create consistency in questions rather than categories over time, while the combination and salience of the responses differ over individual life courses and as a result of demographic change. In addition, while what is typically at stake for census categorical question measurement is consistency, 'inconsistencies' may be central to a concept of ethnicity as fluid and contingent, and therefore be of interest in their own right. Thus some attempts to reduce inconsistency may be unnecessary or even unhelpful. These 
sources of 'inconsistency' may be of interest - as long as it is possible to measure the relevant correlates (out-group attitudes, location, age, sex, income, interview context and so on). For example, Hecht and Ribeau. (Hecht and Ribeau, 1991) find differences in the choice of ethnic label by gender, age and family income. (Travassos and Williams, 2004) also find differences in ethnic group identification by socio-demographic characteristics. In Brazil wealthier people classify themselves and their children - and are classified by others - in lighter-skinned categories (Schwartzman, 2007) see also (Golash-Boza and Darity, 2008). (Telles and Lim, 1998) report similar findings for interviewer reported race/ethnicity with respect to education and income. Under our proposed approach these become not problems for categories but part of the understanding of groups and group identification in their own right.

The implication is that to understand ethnic identity and to construct meaningful groups or categories, requires additionally a range of contextual information: information that is typically gleaned in social surveys. By these means, it may be possible to complement focused psychological studies of ethnic identity with broader social contextual information as well as to bridge the gap between current qualitative approaches to ethnicity research and the statistical analysis of ethnic difference. But to achieve this, care needs to be given to how questions are asked and how they relate to other question content.

\section{A way forward}

Historically the interest in measuring ethnicity has been from census bureaux and other official sources for the purpose of assigning people into ethnic groups to 
facilitate monitoring demographic change and life opportunities for certain ethnic groups. With this objective, the focus has been identifying single measures of ethnicity which yield consistent and reliable results, i.e., stable ethnic groups. Our main conclusion is that it is not possible to measure a complex, multidimensional, fluid concept using a single question at one point in time. Nevertheless, we do think it is possible for survey research to provide a much more sensitive measure of ethnicity, where variation over time and between parents and children in elements of a multi-dimensional measure are seen as assets rather than as problems for consistency.

For most surveys, a categorical question in the form of the Census question would be important not only for range of research purposes concerned with analysis of patterns of association between ethnic groups and other characteristics, as well as detailed understanding of population characteristics and their relationship over time, but also be important for purposes of comparison and calibration with other sources, both census and other surveys. It also enables the relationship between categories and other measures of groupness to be investigated.

However, it is important to address the fact that such a categorical question does not represent ethnic identification or belonging and would not meet the research needs of social psychologists or of those interested in understanding in more detail the meaning and coherence of groups. For such purposes it is surely important to develop questions which tackle who people think they are and how important they consider that to be. 
Subjective measures need to recognize both instabilities in affiliation and multiple affiliations. Such questions would therefore need to incorporate flexibility, through multiple response options, and allow respondents to give some weight to the different elements specified. Incorporating and weighting multiple dimensions would also allow researchers interested only in specific dimensions (religion, national belonging etc.) to use responses directly rather than using ethnic group categories as a proxy for other 'group' concepts. In addition, these dimensions of identity may need to be considered in relation to other aspects of the respondent's experience. For example, we might envisage a series of questions asking about country of birth, nationality, religion, perceived skin colour etc., which would be followed by a question asking which of country of birth, nationality, and all the other dimensions were part of their identity, and for each dimension acknowledged there could be a question attempting to gauge the strength or importance of that dimension, possibly on a scale or rated by terms such as 'very', 'not very' etc.

Individuals may quite appropriately fit into a number of different populations according to the focus of the research and all of these might reflect valid aspects of their self-identity. For example, a respondent might see herself simultaneously as Scottish (upbringing, language/accent, politics, local affiliation), black (politically used to express solidarity with minority, non-white experience), Asian (to suggest antecedents (parents /grandparents or earlier generations from South Asia) and British (to express nationality, citizenship etc.). All these might be important to her, but some aspects might be more 
important, for example, she may consider the most critical element of her identity to be her 'Scottishness'. Additionally, the relative importance could easily vary with context: whether she is in Glasgow or London, whether she is experiencing harassment, whether she is voting, whether she is visiting her parents or being interviewed by a non-Asian interviewer etc. (Hall, 2000, Aspinall, 2002, Hall, 1996). And it could vary over time, in relation to recent national or international events such as wards or personal events such as marriage or bereavement. Clearly not all the subtleties of an individual's identifications could be captured by particular survey questions, but surveys could certainly move towards being able to address more of them and their dynamic relationship with experiences and social context.

It is important not only to measure relevant dimensions (relevant to respondents and researchers), but also to consider the practical impact of acceptability, phrasing, position, mode, and the wider context in which the questions are being asked. The nature of surveys is that there is no opportunity to interrogate responses, and so it remains important to avoid arbitrary responses or to lead respondents to particular answers to ensure that it is possible to measure meaningful concepts robustly. Lessons from methodological research into achieving 'correct' responses from categorical census questions, therefore remain pertinent to more flexible survey measures underpinned by different aims and research agendas.

In thinking about the implementation and long-term value of a new measure of ethnic identity, we would also highlight the relevance of surveys 
To get a valid measure of ethnicity which covers the issues discussed in this paper is a challenge. But the prize is worth the effort. If we are able to get the measure(s) right, then this will open up the rich resources of survey research to a wide range of analysts from different disciplines and allow theoretically robust research. 


\section{References}

AHMAD, W. I. U. \& BRADBY, H. 2007 'Locating ethnicity and health: exploring concepts and contexts', Sociology of Health \& Illness, vol. 29, no. 6 , pp. 795-810.

ASPINALL, P. 2000 'The challenges of measuring the ethno-cultural diversity of Britain in the new millennium', Policy and Politics, vol. 28, no. 1, pp. 109-118.

--- 2001a 'Operationalising the collection of ethnicity data in studies of the sociology of health and illness', Sociology of Health and Illness, vol. 23, no. 6, pp. 829-62.

--- 2002 'Collective terminology to describe the minority ethnic population: the persistence of confusion and ambiguity in usage', Sociology, vol. 36, no. 4, pp. 803-816.

ASPINALL, P. J. 2001b 'Operationalising the collection of ethnicity data in studies of the sociology of health and illness', Sociology of Health \& Illness, vol. 23, no. 6, pp. 829-862.

BALLARD, R. 1996 'Negotiating race and ethnicity: exploring the implications of the 1991 Census', Patterns of Prejudice, vol. 30, no. 3, pp. 3-34.

--- 1997 'The construction of a conceptual vision: 'ethnic groups' and the 1991 UK Census', Ethnic and Racial Studies, vol. 20, pp. 182-94.

BARTH, F. 1969 Ethnic Groups and Boundaries: The Social Organisation of Culture Difference. London: Allen \& Unwin.

BATES, N., et al. 2006 'Questionnaire effects on measurement of race and Spanish origin'. U.S. Census Bureau Research Report Series: Survey Methodology No.2006-12.

BERTHOUD, R. 1998 'Defining ethnic groups: origin or identity?' Patterns of Prejudice, vol. 32, no. 2, pp. 53-63.

BHAVNANI, R., MIRZA, H. S. \& MEETOO, V. 2005 Tackling the Roots of Racism: Lessons for Success. Bristol: The Policy Press.

BHOPAL, R. S. 2002 'Revisiting race/ethnicity as a variable in health research', American Journal of Public Health, vol. 92, pp. 156-157.

BLUM, A. 2002 'Resistance to identity categorization in France', in KERTZER, D. I. \& AREL, D. (eds) Census and Identity: The politics of race, ethnicity, and language in national censuses. Cambridge: Cambridge University Press.

BONNETT, A. 2000 White Identities: Historical and International Perspectives. Harlow: Pearson Education.

BONNETT, A. \& CARRINGTON, B. 2001 'Fitting into the categories or falling between them? Rethinking ethnic classification', British Journal of Sociology of Education, vol. 21, no. 4, pp. 487-500.

BROWN, J. S., HITLIN, S. \& ELDER, G. H. 2006 'The greater complexity of lived race: an extension of Harris and Sim', Social Science Quarterly, vol. 87, no. 2, pp. 411-431.

CALLISTER, P., et al. 2007 'Measuring ethnicity in New Zealand: developing tools for health', Ethnicity \& Health, vol. 12, no. 4, pp. 299-320.

COLE, M. 2003 'Ethnicity, 'status groups' and racialization: a contribution to a debate on national identity in Britain', Ethnic and Racial Studies, vol. 26, no. 5, pp. 962-969. 
COLEMAN, D. \& SALT, J. 1996a 'The ethnic group question in the 1991 Census: a new landmark in British social statistics', in COLEMAN, D. \& SALT, J. (eds) Ethnicity in the 1991 Census: Volume One: Demographic characteristics of the ethnic minority populations. London: HMSO.

--- 1996b 'Ethnicity in the 1991 Census: Volume One: Demographic characteristics of the ethnic minority populations'. London: HMSO.

FARLEY, R. 1997 'Racial trends and differences in the United States'.

GEERTZ, C. 1993 The Interpretation of Cultures. London: Fontana Press.

GOLASH-BOZA, T. \& DARITY, W. 2008 'Latino racial choices: the effects of skin colour and discrimination on Latinos' and Latinas' racial selfidentifications', Ethnic and Racial Studies, vol. 31, pp. 899-934.

HALL, S. 1996 'Introduction: who needs identity?' in HALL, S. \& GAY, P. D. (eds) Questions of Cultural Identity. London: Sage.

--- 2000 'Old and new identities, old and new ethnicities', in BACK, L. \& SOLOMOS, J. (eds) Theories of Race and Racism: A Reader. London and New York: Routledge.

HARRIS, D. \& SIMS, J. J. 2002 'Who is Multi-racial? Assessing the Complexity of Lived Race', American Sociological Review, vol. 67, no. 4, pp. 614627.

HECHT, M. \& RIBEAU, S. 1991 'Sociological roots of ethnic identity: a look at black America', Journal of Black Studies, vol. 21, pp. 501-513.

HELBLING, M. 2009 'Social influence networks and understanding of citizenship', Ethnic and Racial Studies, vol. 32, no. 5, pp. 844-863.

HITLIN, S., BROWN, J. S. \& ELDER, G. H. 2006 'Racial self-categorization in adolescence: multiracial development and social pathways', Child Development, vol. 77, no. 5, pp. 1298-1308.

HOLLOWAY, S. R., et al. 2009 'Place, scale and the racial claims made for multiracial children in the 1990 US Census', Ethnic and Racial Studies, vol. 32, no. 3, pp. 522-547.

HOWARD, K. 2006 'Constructing the Irish of Britain: ethnic recognition and the 2001 UK Censuses', Ethnic and Racial Studies, vol. 26, no. 5, pp. 104123.

HSIAO, J. \& WITTIG, M. A. 2008 'Acculturation among three racial/ethnic groups of host and immigrant adolescents', American Journal of Community Psychology, vol. 42, no. 3-4, pp. 286-297.

HUSSAIN, Y. \& BAGGULEY, P. 2005 'Citizenship, ethnicity and identity: British Pakistanis after the 2001 'riots", Sociology, vol. 39, no. 3, pp. 407425.

ITZIGSOHN, J., GIORGULI, S. \& VAZQUEZ, O. 2005 'Immigrant incorporation and racial identity: racial self-identification among Dominican immigrants', Ethnic and Racial Studies, vol. 28, pp. 50-78.

JACKSON, J. W. \& SMITH, E. R. 1999 'Conceptualizing social identity: A new framework and evidence for the impact of different dimensions', Personality and Social Psychology Bulletin, vol. 25, no. 1, pp. 120-135.

JENKINS, R. 1994 'Rethinking ethnicity: identity, categorization and power', Ethnic and Racial Studies, vol. 17, no. 2, pp. 197-223.

KERTZER, D. I. \& AREL, D. 2002 'Censuses, identity formation, and the struggle for political power', in KERTZER, D. I. \& AREL, D. (eds) Census and Identity: The politics of race, ethnicity, and language in national censuses. Cambridge: Cambridge University Press. 
KYMLICKA, W. 1996 Multicultural Citizenship: A liberal theory of minority rights. Oxford: Clarendon.

LOPEZ, A. 2003 'Collecting and tabulating race/ethnicity data with diverse and mixed heritage populations: A case-study with US high school students', Ethnic and Racial Studies, vol. 26, pp. 931-961.

MARTIN, E., DEMAIO, T. J. \& CAMPANELLI, P. C. 1990 'Context effects for census measures of race and hispanic origin', Public Opinion Quarterly, vol. 54, pp. 551-556.

MARTIN, E. A. \& GERBER, E. 2006 'Methodological Influences on Comparability of Race Measurements: Several Cautionary Examples'. Washington DC: Statistical Research Division, U.S. Census Bureau.

MASSEY, D. S. 1993 'Latinos, poverty and the underclass: a new agenda for research', Hispanic Journal of Behavioral Sciences, vol. 15, no. 4, pp. 449-475.

MAYLOR, U. 2009 'What is the meaning of 'black'? Researching 'black' respondents', Ethnic and Racial Studies, vol. 32, no. 2, pp. 369-387.

MCDONNELL, J. \& DE LOURENCO, C. 2009 'You're Brazilian, right? What kind of Brazilian are you? The racialization of Brazilian immigrant women ', Ethnic and Racial Studies, vol. 32, no. 2, pp. 239-256.

MCKENZIE, K. 1998 'Ethnicity in psychiatric epidemiology', The British Journal of Psychiatry, vol. 172, no. 3, p. 278a.

MCKENZIE, K. \& CROWCROFT, N. S. 1996 'Describing race, ethnicity and culture in medical research', British Medical Journal, vol. 312, p. 1054.

MIN, P. G. \& KIM, Y. O. 2009 'Ethnic and sub-ethnic attachments among Chinese, Korean, and Indian immigrants in New York City', Ethnic and Racial Studies, vol. 32, no. 5, pp. 758-780.

MODOOD, T. 1997 'Culture and identity', in MODOOD, T., et al. (eds) Ethnic Minorities in Britain: Diversity and Disadvantage. London: PSI.

MODOOD, T., BEISHON, S. \& VIRDEE, S. 1994 Changing Ethnic Identities. London: Policy Studies Institute.

MODOOD, T., BERTHOUD, R. \& NAZROO, J. 2002 '“"Race”, racism and ethnicity': a response to Ken Smith', Sociology, vol. 36, no. 2, pp. 419427.

NAGEL, J. 1994 'Constructing ethnicity: creating and recreating ethnic identity and culture', Social Problems, vol. 41, no. 1, pp. 152-176.

NAZROO, J. Y. \& KARLSEN, S. 2003 'Patterns of identity among ethnic minority people: diversity and commonality', Ethnic and Racial Studies, vol. 26 , no. 5 , pp. 902-930.

NOBLES, M. 2002 'Racial categorization and censuses', in KERTZER, D. I. \& AREL, D. (eds) Census and Identity: The politics of race, ethnicity, and language in national censuses. Cambridge: Cambridge University Press.

OFFICE FOR NATIONAL STATISTICS 2003 Ethnic group statistics. A guide for the collection and classification of ethnicity data. London: HMSO.

PEACH, C. 1996 'Ethnicity in the 1991 Census: Volume Two: The ethnic minority populations of Great Britain'. London: HMSO.

PHINNEY, J. S. 1990 'Ethnic Identity in Adolescents and Adults: Review of Research', Psychological Bulletin, vol. 108, no. 3, pp. 499-514.

--- 1992 'The Multigroup Ethnic Measure: a new scale for use with diverse groups', Journal of Adolescent Research, vol. 7, pp. 156-176. 
PHINNEY, J. S. \& ALIPURIA, L. L. 1990 'Ethnic Identity in College Students from Four Ethnic Groups', Journal of Adolescence, vol. 13, pp. 171-183.

PHINNEY, J. S., et al. 2001 'The role of language, parents, and peers in ethnic identity among adolescents in immigrant families', Journal of Youth and Adolescence, vol. 30, no. 2, pp. 135-153.

PHOENIX, A. \& TIZARD, B. 1995 'The identity of mixed parentage adolescents', Journal of Child Psychology and Psychiatry, vol. 36, no. 8, pp. 1399-1410.

PRINGLE, M. \& ROTHERA, I. 1996 'Practicality of recording patient ethnicity in general practice: descriptive intervention study and attitude survey', British Medical Journal, vol. 312, pp. 1080-1082.

RATCLIFFE, P. 1996 'Introduction: social geography and ethnicity: a theoretical, conceptual and substantive overview', in RATCLIFFE, P. (ed) Ethnicity in the 1991 Census: Volume Three: Social geography and ethnicity in Britain: geographical spread, spatial concentration and internal migration. London: HMSO.

RYAN, L. 2007 'Who do you think you are? Irish nurses encountering ethnicity and constructing identity in Britain', Ethnic and Racial Studies, vol. 30, pp. 416-438.

SALT, J. 1996 'Immigration and ethnic group', in COLEMAN, D. \& SALT, J. (eds) Ethnicity in the 1991 Census: Volume One: Demographic characteristics of the ethnic minority populations. London: HMSO.

SALWAY, S. 2008 'Labour market experiences of young UK Bangladeshi men: Identity, inclusion and exclusion in inner-city London', Ethnic and Racial Studies, vol. 31, pp. 1126-1152.

SCHWARTZMAN, L. F. 2007 'Does money whiten? Intergenerational changes in racial classification in Brazil', American Sociological Review, vol. 72, pp. 940-963.

SENIOR, P. A. \& BHOPAL, R. 1994 'Ethnicity as a variable in epidemiological research', British Medical Journal, vol. 309, pp. 327-330.

SILLITOE, K. \& WHITE, P. H. 1992 'Ethnic group and the British Census: the search for a question', Journal of the Royal Statistical Society, series A, vol. 155 , no. 1 , pp. 141-163.

SINGH, S. P. 1997 'Ethnicity in psychiatric epidemiology: need for precision', British Journal of Psychiatry, vol. 171, pp. 305-308.

SKERRY, P. 2000 Counting on the Census? Race, Group Identity, and the Evasion of Politics. Washington, DC: Brookings Institution.

SMITH, K. 2002 'Some critical observations on the use of the concept of "ethnicity" in Modood et al., Ethnic Minorities in Britain', Sociology, vol. 36, no. 2, pp. 399-417.

TELLES, E. E. \& LIM, N. 1998 'Does it matter who answers the race question?: Racial classification and income inequality in Brazil', Demography, vol. 35, no. 4, pp. 465-474.

TRAVASSOS, C. \& WILLIAMS, D. R. 2004 'The concept and measurement of race and their relationship to public health: a review focused on Brazil and the United States', Cad. Saúde Pública, vol. 20, no. 3, pp. 660-678.

UMANA-TAYLOR, A. J., GONZALES-BACKEN, M. A. \& GUIMOND, A. B. 2009 'Latino adolescents' ethnic identity: is there a developmental progression and does growth in ethnic identity predict growth in selfesteem?' Child Development, vol. 80, no. 2, pp. 391-405. 
URLA, J. 1993 'Cultural politics in an age of statistics: numbers, nations, and the making of Basque identity', American Ethnologist, vol. 20, no. 4, pp. 818843.

VEDDER, P. \& VIRTA, E. 2005 'Language, ethnic identity, and the adaptation of Turkish immigrant youth in the Netherlands and Sweden', International Journal of Intercultural Relations, vol. 29, no. 3, pp. 317337.

WARIKOO, N. 2005 'Gender and ethnic identity among second-generation IndoCaribbeans', Ethnic and Racial Studies, vol. 28, no. 5, pp. 803-831.

WEBER, M. 1978 Economy and Society. Edited by G. Roth and C. Wittich. Berkeley: University of California Press.

WIMMER, A. 2008 'The making and unmaking of ethnic boundaries: a multilevel process theory', American Journal of Sociology, vol. 113, no. 4, pp. 970-1022.

XIE, Y. \& GOYETE, K. 1997 'The racial identification of biracial children with one Asian parent: evidence from the 1990 Census', Social Forces, vol. 76, pp. 547-570.

YANCEY, W., ERICKSEN, E. \& JULIANI, R. 1976 'Emergent ethnicity: a review and reformulation', American Sociological Review, vol. 41, no. 3, pp. 391-403.

ZUBERI, T. \& BONILLA-SILVA, E. 2008 'White Logic, White Methods: Racism and Methodology'. Lanham, MD: Rowman \& Littlefield.

JONATHAN BURTON is Research Fellow in the Institute for Social and Economic Research, University of Essex

ADDRESS: ISER, University of Essex, Wivenehoe Park, Colchester CO4 3SQ

Email: jburton@essex.ac.uk

ALITA NANDI is Research Officer in the Institute for Social and Economic Research, University of Essex

ADDRESS: ISER, University of Essex, Wivenehoe Park, Colchester CO4 3SQ

Email: anandi@essex.ac.uk

LUCINDA PLATT is Senior Lecturer in the Institute for Social and Economic Research, University of Essex

ADDRESS: ISER, University of Essex, Wivenehoe Park, Colchester CO4 3SQ

Email: 1platt@essex.ac.uk 